\title{
Tendinopathies and platelet-rich plasma (PRP): from pre-clinical experiments to therapeutic use
}

\author{
Kaux $\mathrm{JF}^{1}$, Drion $\mathrm{P}^{2}$, Croisier $\mathrm{JL}^{3}$, Crielaard $\mathrm{JM}^{1}$
}

Objectives: The restorative properties of platelets, through the local release of growth factors, are used in various medical areas. This article reviews fundamental and clinical research relating to platelet-rich plasma applied to tendinous lesions.

Materials and method: Articles in French and English, published between 1 January 2012 and 31 December 2014. dealing with PRP and tendons were searched for using the Medline and Scopus data bases.

Results: Forty-seven articles were identified which addressed pre-clinical and clinical studies: 27 relating to in vitro and in vivo animal studies and 20 relating to human studies. Of these, five addressed lateral epicondylitis, two addressed rotator cuff tendinopathies, ten dealt with patellar tendinopathies and three looked at Achilles tendinopathies.

Conclusions: The majority of pre-clinical studies show that PRP stimulates the tendon's healing process. However, clinical series remain more controversial and level 1 , controlled, randomised studies are still needed.

Key Words: Tendinopathy, Platelet-rich Plasma, PRP, Growth Factors

\section{Introduction}

The 'restorative' properties of platelets, through the release of growth factors, have been implemented in various medical areas (dentistry, dermatology, orthopaedic and plastic surgery, ophthalmology, etc.), because of their contribution to healing various tissues (bone, skin, muscle, tendons, etc. ${ }^{[1]}$. They may be injected, in situ, in the form of platelet concentrates, commonly known as PRP (platelet-rich plasma), obtained from autologous blood ${ }^{[1]}$.

This innovative treatment has piqued clinicians' interest, particularly specialists in physical medicine and sports traumatology, more so because the production of PRP is relatively easy ${ }^{[2]}$. Although intratendinous injection can slightly increase the blood concentration of growth factors (particularly in vascular endothelial growth factor (VEGF) $)^{[3]}$, PRP no longer appears on the list of doping products (www.wadaama.org), in contrast to other labile blood products. PRP can neither improve muscle mass nor alter the transport of oxygen (particularly because the presence of red blood cells alters PRP quality) ${ }^{[4]}$.

This literature review analyses articles on the use of PRP in tendinous healing (experimental and clinical studies) published between 1 January 2012 and 31 December 2014. Several reviews have already appeared relating to earlier studies $^{[5-15]}$. The results of both pre-clinical and clinical studies were analyzed separately in this review and finally discussed together in order to trying to improve this therapeutic modality. Articles were searched for using the Medline and Scopus databases, by entering, alone and/or combining, the following key words (in French and in English): tenocytes, tendon, tendinopathy, PRP, platelet-rich plasma. The papers with high level of proofs were preferentially selected. However, due to the small number of high level publications, most of the papers were accepted and discussed. Forty seven publications relating to the use of PRP were selected: 27 pre-clinical in vitro and in vivo animal studies and 20 clinical studies in humans. Of these, five addressed lateral epicondylitis; two addressed rotator cuff tendinopathies; ten dealt with patellar tendinopathies; and three looked at calcaneal tendinopathies.

\section{A. Pre-clinical studies}

Several lab studies (in vitro and/or on animals) have already demonstrated that PRP accelerates the healing process and that each growth factor exercises a specific action during the tendon healing process ${ }^{[6]}$. However, new studies allow us to better understand the effect of PRP on tendon healing.

Mazzocca et al., confirm that different PRPs stimulate cell proliferation (muscle, bone and tendon) ${ }^{[16]}$. They did not, however, observe any significant difference between the different preparations used. In contrast, however, it appears that the most concentrated PRPs and those containing white blood cells are less efficient than less concentrated PRPs and strongly concentrated PRPs without white blood cells. Moreover, this same team demonstrated in vitro that the anti-bacterial effect of PRP against Staphylococcus aureus, Staphylococcus epidermis, Propionibacterium acnes and Methicillin-resistant Staphylococcus aureus (MRSA) was not linked to the presence of white blood cells ${ }^{[17]}$. 
In addition to the presence or otherwise of white blood cells in PRP, Galliera et al. observed that platelets actively controlled the recruitment of leukocytes through the intermediary of transforming growth factor $\beta$ (TGF- $\beta)^{[18]}$.

Dragoo et al., compared the inflammatory reaction caused by the infiltration of physiological liquid, blood, PRPs rich in white blood cells and PRPs low in white blood cells in rabbit tendons ${ }^{[19]}$. Five days after infiltration, the PRPs rich in white blood cells lead to a significant inflammatory cellular reaction, similar to that observed following blood infiltration. However, after 14 days, no difference was observed between the four groups. Moreover, McCarrell et al., assessed the effect of four PRPs (PRP with intermediate concentration of platelets $6.10^{5}$ platelets $/ \mu \mathrm{L}$ ) and white blood cells; PRP with intermediate concentrations of platelets and reduced white blood cells; PRP with intermediate concentration of platelets and high concentration of white blood cells $\left(12.10^{5}\right.$ platelets $/ \mu \mathrm{L}$ and white blood cells) on the culture of horse tendons ${ }^{[20]}$. They noted that the PRP with an intermediate concentration of platelets and $a$ high concentration of white blood cells led to higher expression of pro-inflammatory cytokines and catabolic mediators (Interleukin $1 \beta$ (IL-1 $\beta)$, tumor necrosis factor $\alpha($ TNF- $\alpha)$ ) as well as lower collagen synthesis. Moreover, the PRP with high concentrations of platelets and white blood cells led to a paradoxical effect on collagen synthesis, while also presenting an increase in inflammatory mediators. These observations were confirmed by Boswell et al., who also noted in equine tendon cultures that when platelet concentrations were too high (despite low concentrations of white blood cells) this reduced tendon metabolism and

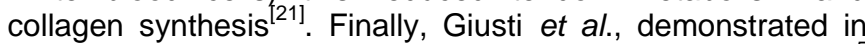
human tenocyte cultures that concentrations of between $5.10^{5}$ and $1.10^{6}$ platelets/ $\mu \mathrm{L}$ stimulated cell proliferation and migration as well as collagen production ${ }^{[22]}$. On the other hand, higher platelet concentrations have an inhibitive effect both in terms of cell metabolism and collagen synthesis.

In addition to the fact that PRP stimulates cell proliferation and collagen synthesis, Jo et al., demonstrated that platelet activation through thrombin and calcium is more efficient that calcium activation alone ${ }^{[23]}$.

In vitro, however, PRP does not enable the reversal of degenerative tendinopathies, characterised by the presence of lipid deposits, the accumulation of proteoglycans as well as the presence of calcification ${ }^{[24]}$. However, still in vitro, PRP does enable the differentiation of tenocyte stem cells and inhibits the differentiation in adipocytes, chondrocytes and osteocytes, which can hamper tendon healing ${ }^{[25]}$.

Muto et al., demonstrated that PRP protects against the deleterious effects of triamcinolones on cells (reduction in cell viability and stimulation of apoptosis) from human rotator cuffs $^{[26]}$. Moreover, Carofino et al., studied the effect of two different PRPs obtained from human blood, on isolated tenocytes in the long head of the biceps ${ }^{[27]}$. These were cultured in PRP and either methylprednisolone, lidocaine or bupivacaine. They observed that corticoids and, particularly, local anaesthetics, alone or combined, reduced the positive effects of PRP on tenocyte proliferation and viability. These observations were corroborated by those of Bausset et al., who showed that local anaesthetics which may be used as painkillers during PRP infiltration in clinical practice, could compromise the potential therapeutic potential of platelets ${ }^{[28]}$. They reduce platelet aggregation but will not interfere with the release of their growth factors. Finally, to reduce pain during infiltration, they recommend the use of smaller needles (30G), because they do not alter platelet function. During the study of the effects of PRP on biological activity of fibroblasts in human rotator cuffs, Wang et al., observed greater cell proliferation and collagen synthesis when PRP was present in comparison with foetal veal serum ${ }^{[29]}$. This is supported by other studies which show higher cell proliferation, better alignment of collagen fibres and better tendon biomechanical properties when PRP is concentrated up to five times ${ }^{[30]}$. Kaux et al., demonstrate, using rats' Achilles tendon lesion models that the early stages of healing (five days) are stimulated by PRP: acute collagen synthesis and better traction resistance ${ }^{[31]}$. Within this group of PRP, FernandezSarmiento et al., observed early healing progress, better collagen organisation, and a reduction in fibroblast and vascular density ${ }^{[32]}$. These observations are confirmed by other series using lesion models of rats' rotator cuffs ${ }^{[33]}$.

In an in vitro model on rabbits' tendon cells and in vivo on rats' Achilles tendons, Zhang et al., proved that the anti-inflammatory effect of PRP is essentially linked to HGF (hepatocyte growth factor) ${ }^{[34]}$. HGF leads to a reduction in the expression of cyclooxygenases (COX) 1 and 2, as well as prostaglandins (PGE2).

In terms of the growth factors involved in the healing process, Solchaga et al., noted that $10 \mu \mathrm{g}$ platelet-derived growth factor (PDGF-BB) stimulated healing in rats' Achilles tendons, in contrast to $3 \mu \mathrm{g}$ of PDGF-BB, triamcinolone, but also $P R P^{[35]}$. In contrast to the deleterious effect of VEGF165, Kaux et al., observed that VEGF-111, another VEGF-A isoform, stimulated the early phases of the healing process in rats' Achilles tendons, by improving bio-mechanical properties $^{[36]}$.

Finally, in addition to platelet effectiveness on healing in line with a chemical tendinopathy model (platelet and calcaneal tendons in rats), Dallaudière et al., did not show evidence of local toxicity of PRP ${ }^{[37]}$.

In conclusion, the majority of pre-clinical studies show a beneficial effect of PRP on the proliferation of tenocytes, collagen synthesis and the tendon healing process. In order to optimise efficiency, it would appear that platelet concentration should be lower than $10^{6}$ platelets $/ \mu \mathrm{L}$ and that white blood cells should be absent.

\section{B. Clinical studies:}

PRPs are used in the context of chronic tendinopathies in injectable form ${ }^{[38]}$. For some years, it has been used increasingly regularly, more specifically in the area of physical medicine and sports traumatology ${ }^{[11]}$. The objective is to heal tendinopathies which are particularly resistant to other conservative treatments (eccentric physical therapy, shock waves, etc.) and thus to avoid surgery. In a certain number of cases, the aim is also to reduce the duration of functional impotence and to encourage an early return to physical activity. However, currently the use of these PRPs remains a topic of debate and even controversy ${ }^{[7-15]}$.

Table 1 presents the clinical studies discussed in this review.

\section{Epicondylites}

In a prospective three-month study, without a control group 
(level 3), Silvestre et al., report on the clinical evolution of 26 patients who had suffered from evolving lateral epicondylitis for more than six months and who had received PRP infiltration ${ }^{[39]}$. They noted that pain, assessed on simple verbal scale, was significantly improved, a well as the Quick disabilities of the arm, shoulder and hand (DASH) score. Ultrasound observations showed the fissure had disappeared in $65 \%$ of patients, as well as a reduction in the pathological area and Doppler hyperaemia in $27 \%$ of subjects. In their controlled, randomised study (level 1), Omar et al., compared the effect of PRP or corticoid infiltration in 30 patients over a period of six weeks. They observed a positive change on the visual analogue scale (VAS) and DASH score within the two groups, but no significant difference between them ${ }^{[40]}$.

In their longitudinal six-month study (level 4) of six patients who had received an injection of $3 \mathrm{ml}$ of PRP under ultrasound, Chaudhury et al., observed a positive change in the tendon's ultrasound structure, with a trend towards increased vascularisation at the myotendinous junction ${ }^{[41]}$.

The randomised, controlled, double-blind study (level 1) by Krogh et al., did not show any difference after PRP, corticoid or physiological liquid infiltration in the context of epicondylitis over a period of three months ${ }^{[42]}$. However, patients who received $\mathrm{PRP}$ infiltration started to improve, while those who received corticoid infiltration (resulting in fast improvement in pain in the very short term), indicated the progressive return of pain.

Recently, in their randomised and controlled study (level 1) of 230 patients, Mishra et al., compared a PRP group to an active control group receiving an injection of local anaesthetic ${ }^{[43]}$. After 12 weeks, there was no difference between the two groups in terms of VAS when extending the wrist against resistance and the patient-rated tennis elbow evaluation (PRTEE) self-assessment score. At the end of the 24 week follow-up period, significantly positive clinical changes were observed in the PRP group of patients.

To summarise, although studies with low levels of proof on the use of PRP for lateral epicondylitis currently appear to be favourable, the small number of series with a high standard of proof are still contradictory and more randomised controlled studies are still needed.

\section{Tendon lesions in rotator cuffs}

The randomised, controlled study by Rha et al., (level 1) compared the value of two PRP infiltrations in 39 patients affected by tendinopathy of the rotator cuff, compared to two dry needle insertions guided by ultrasound, over a period of six months ${ }^{[44]}$. After the first intervention, the two groups evolved identically. However, after the second infiltration of PRP, a clinical improvement (in pain and mobility of the shoulder) was observed in comparison with the control group.

In their randomised, controlled study (level 1), Kesikburun et al., assessed the effect in 40 patients of an injection of either PRP or physiological liquid ${ }^{[45]}$. After 12 months, no difference could be observed between the two groups in terms of pain, quality of life, handicap and range of motion of the shoulder.
To summarise, the very small number of studies with a high standard of proof on the use of PRP for tendinopathies of the rotator cuff currently remain contradictory. Up to now, it remains hard to draw a conclusion.

\section{Patellar tendinopathies}

The prospective, randomised and controlled (level 1) study by Almeida et al., specified that PRP improved healing at the puncture site (patellar tendon) required for ligamentoplasties (Kenneth-Jones type) of the anterior cruciate knee ligament ${ }^{[46]}$.

The prospective 18-month study (level 3) by Gosens et al., compared 14 patients who had already received treatment (cortocoids or ethoxysclerol and/or surgery) with 22 patients who had never had any infiltrative or surgical treatment ${ }^{[47]}$. They all took part in eccentric physical therapy before and after the injection. After four weeks, the patients were able to gradually restart their sporting or recreational activities. An improvement in Victorian Institute of Sport Assessment for patellar tendinopathy (VISA-P) scores, VAS and pain during daily activities was seen in both groups, but more significantly so for the patients who had never had 'invasive' treatment before PRP infiltration.

Rowan et al., report on the positive development and return to prior athletic form within six months of a 23-year old elite athlete (level 4) who had received multidisciplinary treatment including PRP infiltration for patellar tendinopathy ${ }^{[48]}$.

In their longitudinal study (level 3) of 46 patients who had received three PRP infiltrations two weeks apart, with a minimum monitoring period of up to 36 months (average of 49 \pm 8 months), Filardo et al., demonstrated a positive evolution two months after infiltration, continuing at six months and until the end of the follow up period ${ }^{[49]}$. Eighty percent of patients had resumed their sporting activities. Patients with bilateral problems and whose symptoms had lasted the longest, however, evolved less well.

In their randomised and controlled study (level 1), Vetrano et al., assessed the effect of PRP over three treatments with focal shock waves in 46 patients suffering from patellar tendinopathy ${ }^{[50]}$. After two months, the two groups evolved in a similar way. However, after six and twelve months of follow up, the PRP patients presented better progress than the group treated with shock waves.

As part of their randomised and controlled study (level 1), Dragoo et al., compared the effect of PRP infiltration to the introduction of a dry needle guided by ultrasound in 23 patients ${ }^{[51]}$. The two groups took part in eccentric physical rehabilitation following infiltration. Although evolution at 12 weeks is better in the PRP group, this beneficial effect dissipates over time and, at 26 weeks, no difference could be seen between the two groups.

Charousset et al., followed 28 high level athletes (level 4) who received three consecutive infiltrations of PRP under ultrasound control ${ }^{[52]}$. At the end of the two year follow-up period, the subjects reported improvements in their symptoms and function, enabling them to get back to their earlier athletic condition more quickly. Moreover, they observed that tendons regained their normal $\mathrm{MRI}$ architecture. 
Kaux et al., followed 20 patients suffering from chronic patellar tendinopathy in a longitudinal cohort study (level 3) following 'standardised' PRP infiltration, obtained by an apheresis machine combined with progressively intense submaximal eccentric physical exercise ${ }^{[53]}$. Evolution at six weeks and three months showed a significant reduction in pain and self-assessed scores, as well as in pain during maximal eccentric effort applied to the quadriceps, but no imaging improvements. The youngest patients appeared to improve more following this PRP treatment.

Two longitudinal studies (level 3 and 4) relating to postinfiltration physical therapy have been published ${ }^{54,55]}$. The two programmes were based on eccentric physical therapy following a period of pain-relieving physical therapy and recovery of normal range of movement in the joint. However, the protocol used by Kaux et al., begins eccentric submaximal physical therapy earlier than that of Van Ark et al. These eccentric exercises are gradually combined with isometric work followed by concentric strengthening work on the quadriceps as well as proprioceptive exercises. At the end of the physical therapy treatment, which is supervised by a physiotherapist, the patients can continue self-led treatment in the long term.

Bowman et al., report that three patients (level 4) who had already received $\mathrm{PRP}$ infiltration for unresponsive patellar tendinopathy, experienced an increase in painful symptoms leading to an inability to take part in sport, but also in increase in the thickness of the tendon and, in one patient, osteolysis of the patellar pole ${ }^{[56]}$. Fink et al., also observed an osteolysis of the distal pole of the patella in one patient who had worsening pain and thickening of the patellar tendon after one infiltration of PRP (Level 4). Kaux et al., also published (level 4) the case of a particularly exuberant inflammatory reaction in a Type-1 diabetic patient following a PRP infiltration for patellar tendinopathy. Evolution was favourable at six months under pain-relieving and antiinflammatory treatment ${ }^{[57]}$.

To summarise, studies on the use of PRP for patellar tendinopathies currently appear to be favourable, but high standard of proof studies remain fairly contradictory. It appears that eccentric physical therapy is necessary following PRP infiltration. More randomised controlled series are needed.

\section{Calcaneal tendinopathies}

Over a period of three months, Silvestre et al., followed 32 patients (level 3) with Achilles tendonitis who had received ultrasound-guided PRP infiltration ${ }^{[58]}$. After one month, 22 patients were completely cured, and after two months, 28 were completely cured, with a favourable evolution in tendinous echostructure and a reduction in Doppler hyperaemia at three months. Only four patients did not see any clinical improvement and were operated upon.

In their four-year longitudinal study (level 3) of 27 patients suffering from chronic Achilles tendinopathy, following three PRP infiltrations two weeks apart, Filardo et al., reported very positive changes in self-assessed status ${ }^{[59]}$. The patients who had suffered for the longest had more difficulties in returning to sporting activity.
Finally, Murawski et al., conducted a retrospective study (level 4) on 32 patients over six months ${ }^{[60]}$. At the end of the follow-up period, 25 subjects were asymptomatic and had resumed their sporting activities. The seven others experienced no improvements in their pain and were operated upon. Only four patients presented MRI imaging improvements.

To summarise, studies on the use of PRP for calcaneal tendinopathies currently appear to be positive. However, no high standard of proof studies have taken place since the unfavourable study by de Vos in 2010 which did not report any improvement after an infiltration of leukocyte rich PRP compared to placebo (saline injection) ${ }^{[61]}$.

\section{Discussion}

By releasing different platelet growth factors, PRPs are a new treatment for chronic tendinopathies ${ }^{[15]}$ : the ease of use, the relatively low cost, and the low invasive nature of the treatment are complementary arguments. Up to now, the reported side effects remain benign ${ }^{[56,57]}$. No relationship has been established between growth factor and possible carcinogenesis. Care should be taken, however, to ensure that any undesirable side effects are actually published. Currently, only a bleeding disorder, a disorder of the skin covering (infection, psoriasis) next to the lesion could be reasonably considered as contra-indication of the use of PRP in the treatment of tendinopathies. This treatment has been used for several years in different surgical specialities with favourable clinical results ${ }^{[62,63]}$. Despite the effectiveness of PRP on tissue regeneration in vitro and in animals, little clinical proof is currently available in relation to tendinopathies.

The rare controlled, randomised and blind studies which exist appear to contradict one another ${ }^{[40,42,44,50,51,61]}$. Can the type of tendon change the healing response? Would this be different for certain voluminous tendons (patellar) compared to others (epicondylian, rotator cuff, etc. ${ }^{[73]}$ ? Studies on the patellar tendon appear to be more positive than other tendons. However, as already observed in previous reviews on PRP ${ }^{[5-15]}$, the more recent studies cannot conclude that $\mathrm{PRP}$ is really efficient in the treatment of tendinopathy, even if most of the low level studies remain very encouraging. Moreover, many of the authors of the articles reporting success of PRP application (essentially with leukocytes rich PRP) have conflicts of interest. PRPs are injected into the tendinous lesion, possibly guided by ultrasound (under aseptic conditions) to improve the accuracy of this treatment by a correct positioning of the needle ${ }^{[74-76]}$. A percutaneous tenotomy using a needle (guided by ultrasound) could also be carried out during the infiltration ${ }^{[77]}$.

Moreover, studies appear to be difficult to compare because there is no consensus on preparatory methods, qualitative characteristics of PRP (volume, platelet concentration, presence of leukocytes and erythrocytes ${ }^{[64-67]}$, the infiltration technique, or the post-injection therapy protocol ${ }^{[11,15,54,55,68]}$ ). Indeed, different techniques collate different platelet volumes and concentrations: lab techniques which have been used in the past from an analytical perspective can be distinguished from recent commercial techniques ${ }^{[64-67]}$. Currently, the optimal concentration of platelets used in the treatment of tendinous lesions, has not yet been validated. 


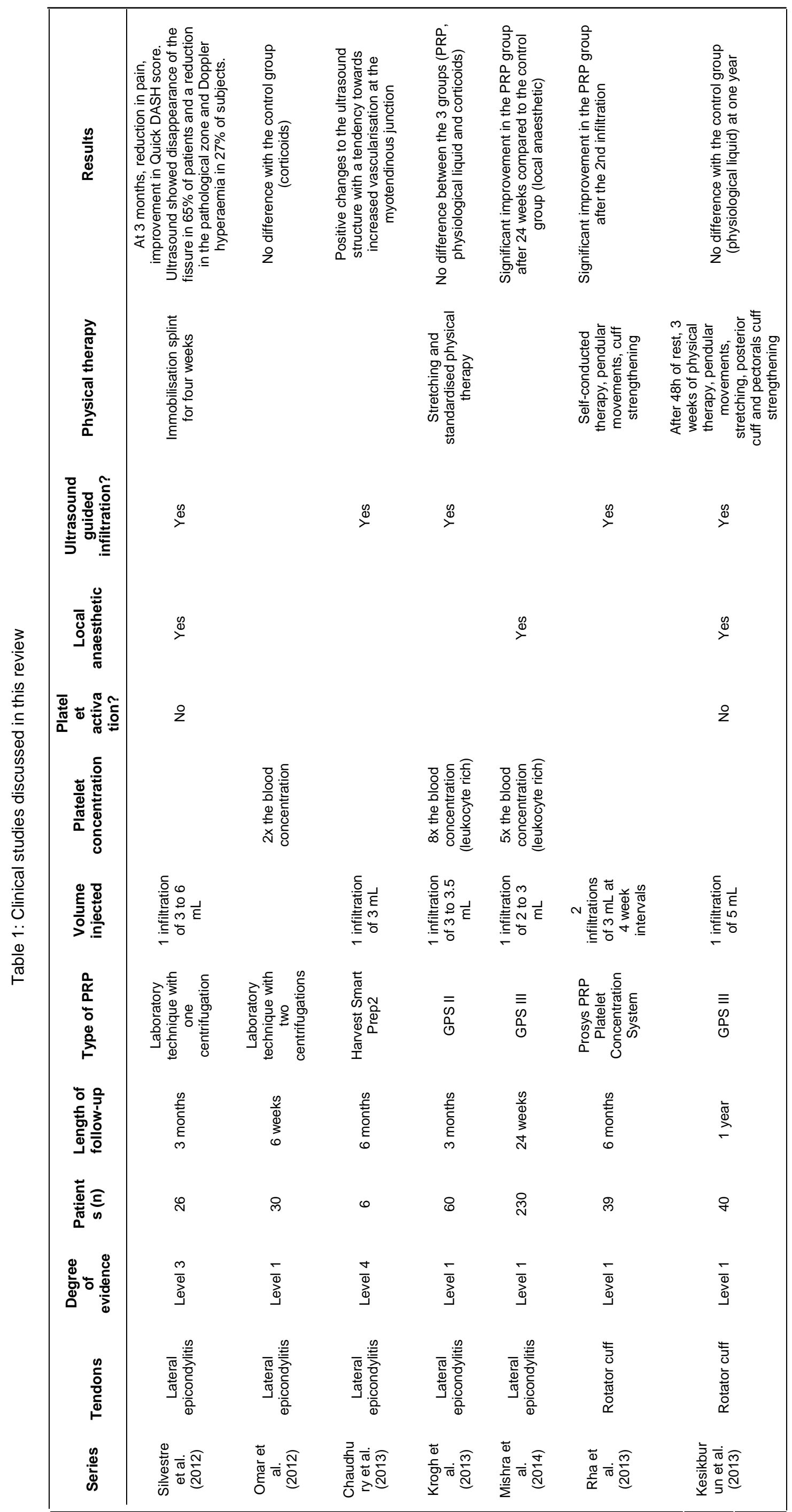




\begin{tabular}{|c|c|c|c|c|c|c|c|}
\hline 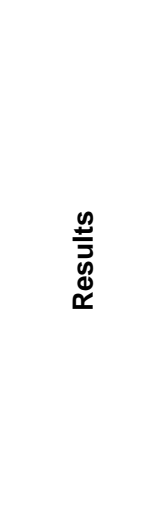 & 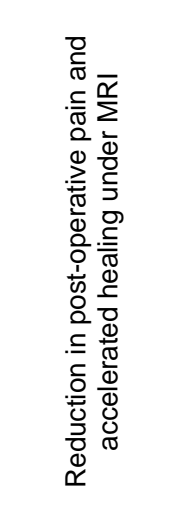 & 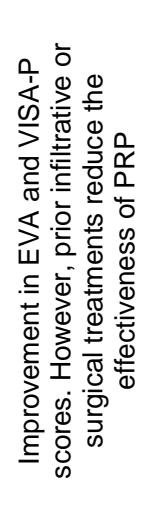 & 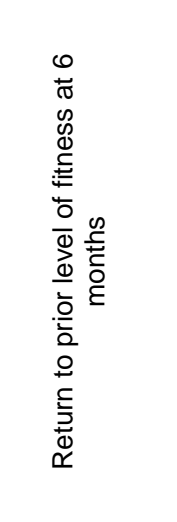 & 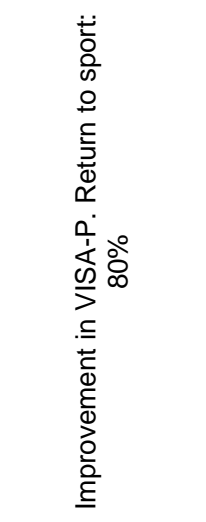 & 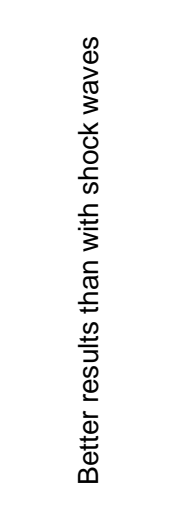 & 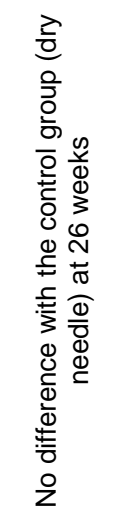 & 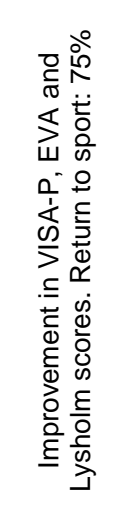 \\
\hline 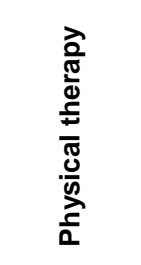 & & 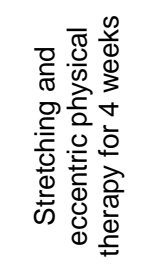 & 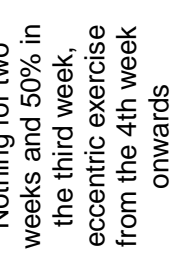 & 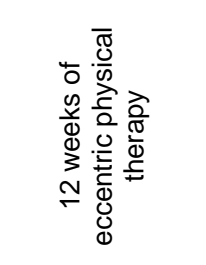 & 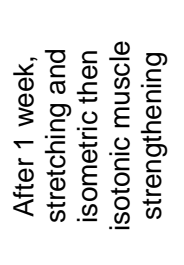 & 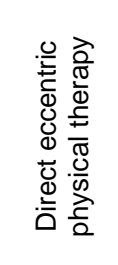 & 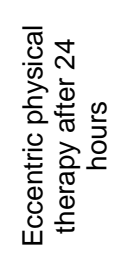 \\
\hline 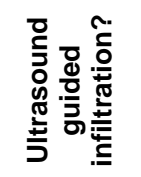 & & & $\stackrel{\mathscr{D}}{>}$ & $\stackrel{\infty}{\nu}$ & $\stackrel{\infty}{>}$ & $\stackrel{\infty}{\succ}$ & $\stackrel{\infty}{>}$ \\
\hline 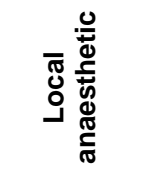 & 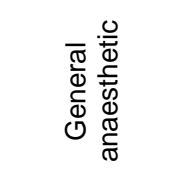 & $\stackrel{\infty}{\rightleftharpoons}$ & & & 운 & $\stackrel{\Perp}{\supset}$ & 을 \\
\hline 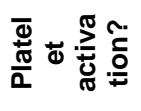 & $\begin{array}{l}\vec{E} \\
\infty \\
0 \\
0 \\
0\end{array}$ & co & & 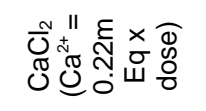 & & & \\
\hline 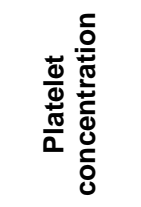 & 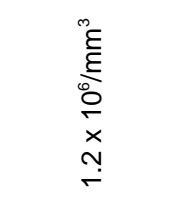 & & & & 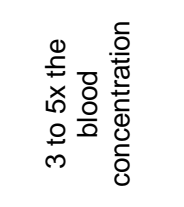 & 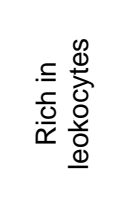 & \\
\hline 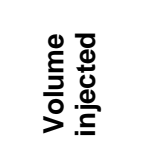 & $\overline{\mathbb{\Phi}}$ & 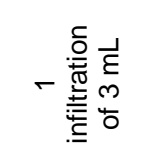 & 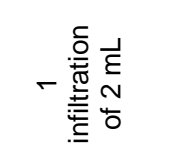 & 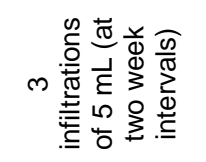 & 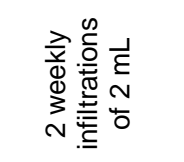 & 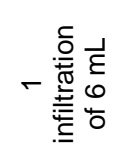 & 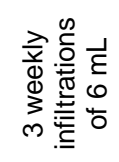 \\
\hline 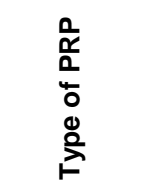 & 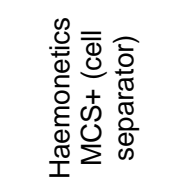 & 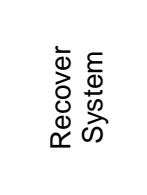 & & 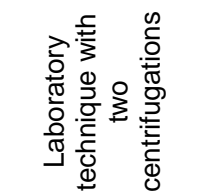 & 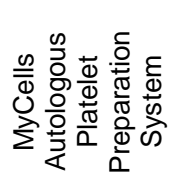 & $\begin{array}{l}\equiv \\
0 \\
0 \\
0\end{array}$ & $\frac{0}{4}$ \\
\hline 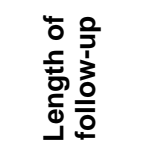 & 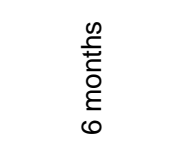 & 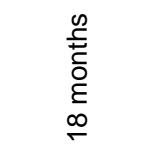 & 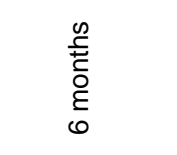 & 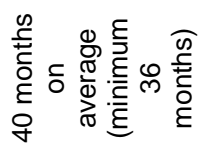 & 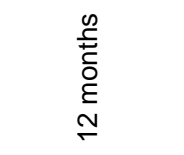 & $\begin{array}{l}\infty \\
\stackrel{0}{0} \\
\Phi \\
\sum^{0} \\
\stackrel{N}{N}\end{array}$ & 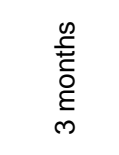 \\
\hline 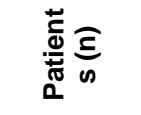 & $\hat{N}$ & ஜ্ল & - & F & o & 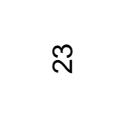 & $\stackrel{\infty}{N}$ \\
\hline 离 & $\bar{\Xi}$ & $\stackrel{\sim}{\Phi}$ & $\stackrel{+}{\stackrel{\oplus}{\Phi}}$ & $\stackrel{m}{\stackrel{m}{\Phi}}$ & $\stackrel{\bar{\Phi}}{\stackrel{\bar{\omega}}{\lrcorner}}$ & $\stackrel{\bar{\Phi}}{\stackrel{\tau}{\Phi}}$ & 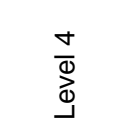 \\
\hline 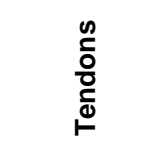 & $\frac{\frac{\pi}{\bar{\sigma}}}{\frac{\overline{0}}{\pi}}$ & $\frac{\frac{\pi}{\bar{\sigma}}}{\frac{\bar{\sigma}}{\pi}}$ & $\frac{\frac{\bar{\pi}}{\overline{0}}}{\frac{\bar{d}}{\pi}}$ & $\frac{\frac{\pi}{\pi}}{\frac{\overline{0}}{\pi}}$ & $\frac{\frac{\pi}{\bar{\sigma}}}{\frac{\bar{\sigma}}{\pi}}$ & $\frac{\frac{\bar{\pi}}{\overline{0}}}{\frac{\bar{d}}{\bar{\pi}}}$ & $\frac{\overline{\frac{\pi}{0}}}{\overline{\bar{\sigma}}}$ \\
\hline$\frac{\mathscr{E}}{\mathscr{\varpi}}$ & 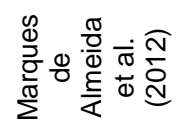 & 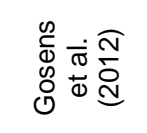 & 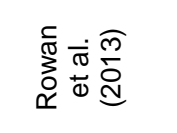 & 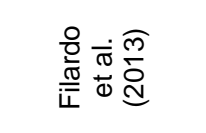 & 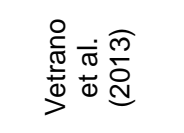 & 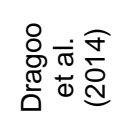 & 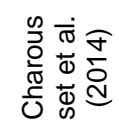 \\
\hline
\end{tabular}




\begin{tabular}{|c|c|c|c|c|c|c|}
\hline 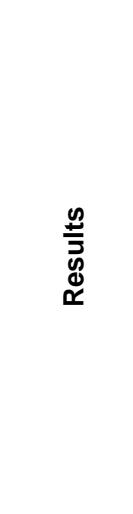 & 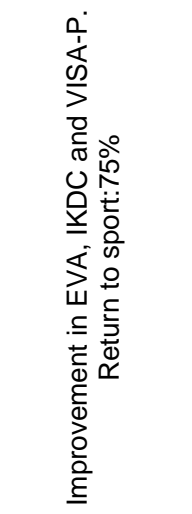 & 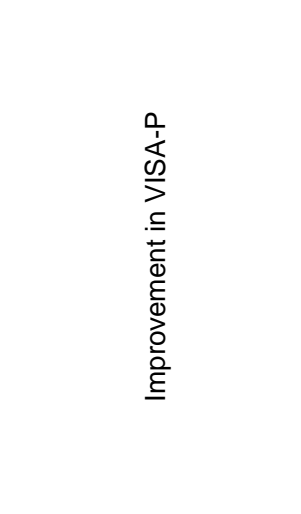 & 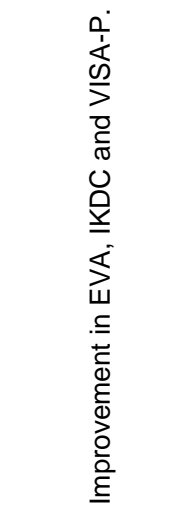 & 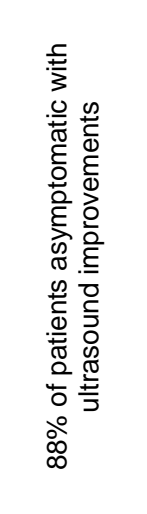 & 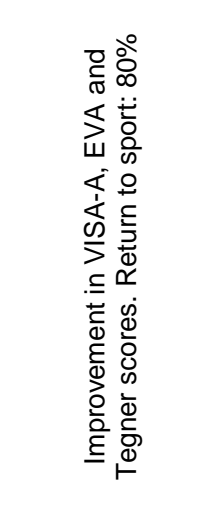 & 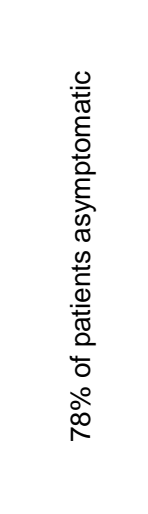 \\
\hline 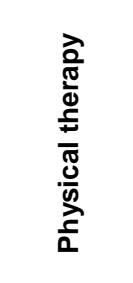 & 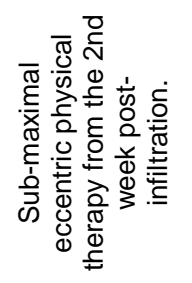 & 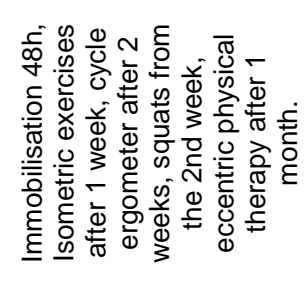 & 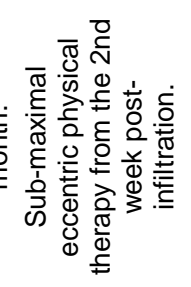 & 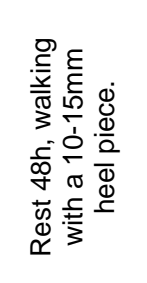 & 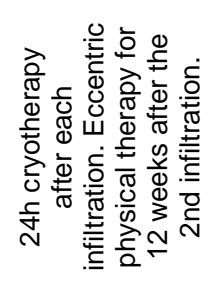 & 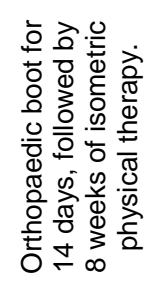 \\
\hline 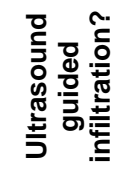 & z & $\stackrel{\infty}{\succ}$ & & $\stackrel{\infty}{\supset}$ & $\stackrel{\mathscr{D}}{>}$ & \\
\hline 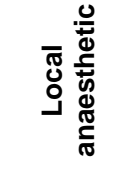 & z & & z & $\stackrel{\infty}{\rightleftharpoons}$ & 우 & $\stackrel{\infty}{>}$ \\
\hline 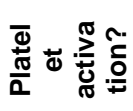 & 홍휴 & & 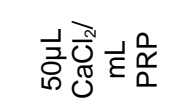 & & 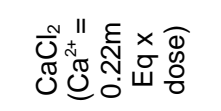 & \\
\hline 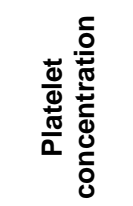 & 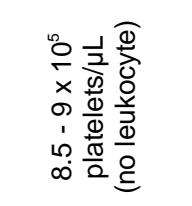 & & 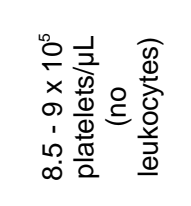 & 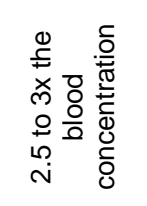 & 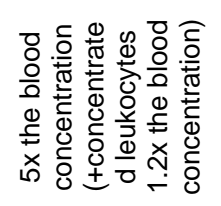 & \\
\hline 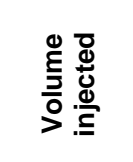 & 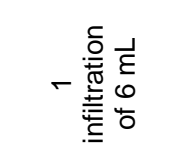 & 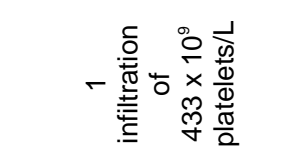 & 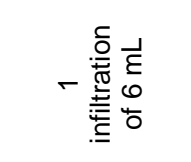 & & 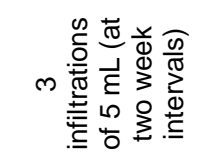 & 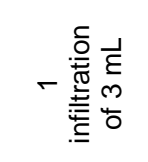 \\
\hline 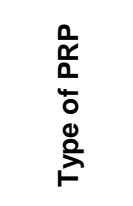 & 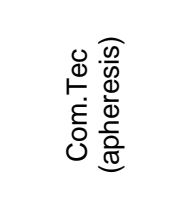 & O) & 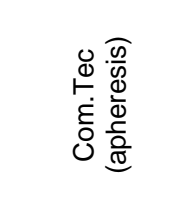 & 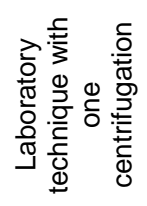 & 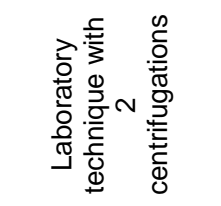 & 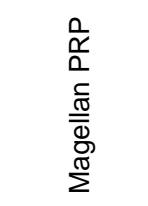 \\
\hline 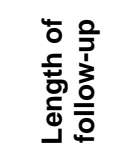 & 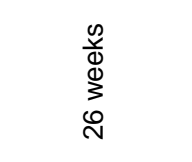 & $\begin{array}{l}\infty \\
\stackrel{\infty}{d} \\
\Phi \\
\sum_{\infty} \\
\stackrel{N}{N}\end{array}$ & 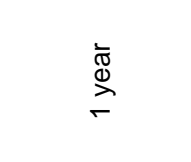 & 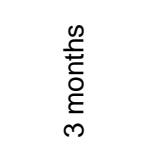 & 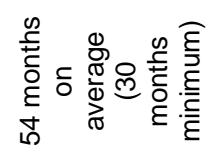 & $\begin{array}{l}\stackrel{0}{c} \\
\stackrel{ \pm}{ \pm} \\
\stackrel{0}{E} \\
0\end{array}$ \\
\hline 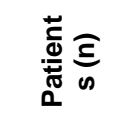 & 尺ి & L & ஓ & $\widetilde{\infty}$ & $\hat{N}$ & $\widetilde{ల}$ \\
\hline 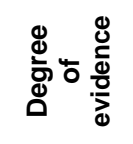 & $\stackrel{m}{\stackrel{m}{\omega}}$ & $\stackrel{+}{\stackrel{\Phi}{\Phi}}$ & $\frac{m}{\Phi}$ & $\stackrel{m}{\stackrel{m}{\Phi}}$ & $\frac{m}{\stackrel{m}{a}}$ & $\underset{\Phi}{\stackrel{\sigma}{\Phi}}$ \\
\hline $\begin{array}{l}0 \\
\stackrel{0}{0} \\
\stackrel{0}{0} \\
\stackrel{0}{\circ}\end{array}$ & $\frac{\frac{\bar{\sigma}}{\bar{w}}}{\frac{\bar{\sigma}}{\pi}}$ & $\frac{\frac{\pi}{\omega}}{\frac{\bar{\omega}}{\pi}}$ & $\frac{\frac{\bar{\pi}}{\bar{\omega}}}{\frac{\pi}{\pi}}$ & 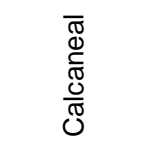 & 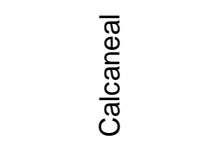 & $\begin{array}{l}\overline{\widetilde{J}} \\
\stackrel{\mathbb{E}}{\pi} \\
\frac{\mathscr{N}}{\pi} \\
0\end{array}$ \\
\hline $\begin{array}{l}\frac{\mathscr{E}}{\bar{\varpi}} \\
\text { ஸे }\end{array}$ & 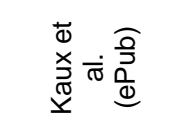 & 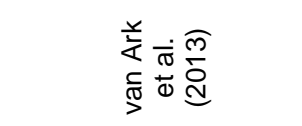 & 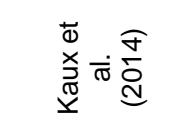 & 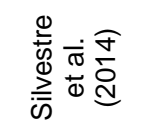 & 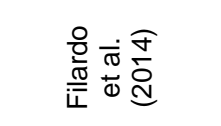 & 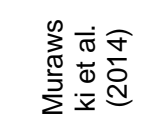 \\
\hline
\end{tabular}


However, the literature raises the following elements:

- a platelet concentration less than $10^{6}$ platelets $/ \mu \mathrm{L}$ (three to four times the blood platelet concentration) would be optimal, while a concentration higher than $12.10^{5}$ platelets would have a paradoxical effect of inhibiting collagen synthesis ${ }^{[20,69]}$

- a total lack of white blood cells, which are likely to slow down healing due to the early occurrence of a higher local inflammatory reaction ${ }^{[19,70]}$ and the presence of pro-inflammatory factors (cytokines and metalloproteinases) likely to damage the extracellular matrix $^{[65,71]}$. PRPs containing leukocytes reduce collagen synthesis ${ }^{[20] \text {. }}$

- the lack of red blood cells because these, once lysed, release various free radicals, similar to those of leukocytes, also likely to damage neighbouring tissues $^{[65,72]}$.

Anti-inflammatories are forbidden from Day -10 to Day +21 , due to their inhibitory effect on PRP action ${ }^{[1,78]}$. It appears that studies where eccentric physical therapy takes place report better results than those with rest or classic rehabilitation techniques ${ }^{[54,55]}$; in fact, the PRPs trigger a healing process, subsequently developed through the vector of eccentric forces ${ }^{[68]}$.

The IOC coordinated the drafting of three articles on PRP $^{[75,79,80]}$ confirming the medical-sporting value of this treatment. It recommends that the injection is guided by ultrasound in order to ensure the correct position of the needle ${ }^{[75]}$. A few minutes after infiltration, PRPs diffuse beyond the infiltrated area and the lesion site, singularly questioning the value of ultrasound-guided infiltrations ${ }^{[81]}$. Moreover, currently there is no consensus on the intratendinous and/or peritendinous site of the infiltration.

\section{Conclusion}

Experimentally, PRP, through the release of different growth factors, stimulates tendinous healing. This treatment should optimise healing in pathological human tendons. It should be examined whether PRP improve tendinous healing in the same way in humans as in animals ${ }^{[82]}$. Up to now, even if PRP seems to be safe and efficient to treat chronic tendinopathies non-responsive to classical conservative treatments, further high standard of proof series should enable this promising technique to be standardised and to optimise the clinical results.

\section{References}

1. Kaux JF, Degrave N, Crielaard JM. Platelet rich plasma : traitement des tendinopathies chroniques ? Revue de la littérature. J Traumatol Sport. 2007;24(2):99-102.

2. Kaux JF, Forthomme B, Le Goff C, Crielaard JM, Croisier JL. Current Opinions on Tendinopathy. J Sports Sci Med. 2011;10(2):238-53.

3. Wasterlain AS, Braun HJ, Harris AH, Kim HJ, Dragoo JL. The systemic effects of platelet-rich plasma injection. Am J Sports Med. 2013;41(1):186-93.

4. Mei-Dan O, Lippi G, Sanchez M, Andia I, Maffulli N Autologous platelet-rich plasma: a revolution in soft tissue sports injury management? Phys Sportsmed. 2010;38(4):127-35.
5. de Vos RJ, van Veldhoven PL, Moen MH, Weir A, Tol JL, Maffulli N. Autologous growth factor injections in chronic tendinopathy: a systematic review. $\mathrm{Br}$ Med Bull. 2010;95:63-77.

6. Taylor DW, Petrera M, Hendry M, Theodoropoulos JS. A systematic review of the use of platelet-rich plasma in sports medicine as a new treatment for tendon and ligament injuries. Clin J Sport Med. 2011;21(4):344-52.

7. Kaux JF, Crielaard JM. Tendinopathies et plasma riche en plaquettes (PRP): applications cliniques. Revue de la littérature. J Traumatol Sport. 2012;29:174-8.

8. Ahmad Z, Brooks R, Kang SN, Weaver H, Nunney I, Tytherleigh-Strong G, Rushton N. The effect of plateletrich plasma on clinical outcomes in lateral epicondylitis. Arthroscopy. 2013;29(11):1851-62.

9. Baksh N, Hannon CP, Murawski CD, Smyth NA, Kennedy JG. Platelet-rich plasma in tendon models: a systematic review of basic science literature. Arthroscopy. 2013;29(3):596-607

10. Jiang $\mathrm{D}$, Wang $\mathrm{JH}$. Tendinopathy and its treatment with platelet-rich plasma (PRP). Histol Histopathol. 2013;28(12):1537-46.

11. Kaux JF, Crielaard JM. Platelet-rich plasma application in the management of chronic tendinopathies. Acta Orthop Belg. 2013;79(1):10-5.

12. Andia I, Latorre PM, Gomez MC, Burgos-Alonso N, Abate $\mathrm{M}$, Maffulli N. Platelet-rich plasma in the conservative treatment of painful tendinopathy: a systematic review and meta-analysis of controlled studies. $\mathrm{Br}$ Med Bull. 2014;110(1):99-115.

13. Bouvard M, Eichene B. Traitement par PRP. Seconde partie : les lésions tendineuses. J Traumatol Sport. 2014;31(4):228-234.

14. de Vos RJ, Windt J, Weir A. Strong evidence against platelet-rich plasma injections for chronic lateral epicondylar tendinopathy: a systematic review. $\mathrm{Br} J$ Sports Med. 2014;48(12):952-6.

15. Smets F, Croisier JL, Forthomme B, Crielaard JM, Kaux JF. Applications cliniques du Plasma riche en plaquettes (PRP) dans les lésions tendineuses : revue de la littérature. Science \& Sports. 2012; 27(3),141-153.

16. Mazzocca AD, McCarthy MB, Chowaniec DM, Dugdale EM, Hansen D, Cote MP, Bradley JP, Romeo AA, Arciero RA, Beitzel K. The positive effects of different platelet-rich plasma methods on human muscle, bone, and tendon cells. Am J Sports Med. 2012;40(8):1742-9.

17. Intravia J, Allen DA, Durant TJ, McCarthy MB, Russell R, Beitzel K, Cote MP, Dias F, Mazzocca AD. In vitro evaluation of the anti-bacterial effect of two preparations of platelet rich plasma compared with cefazolin and whole blood. Muscles Ligaments Tendons J. 2014;4(1):79-84.

18. Galliera E, Corsi MM, Banfi G. Platelet rich plasma therapy: inflammatory molecules involved in tissue healing. J Biol Reg Homeo Ag. 2012;26(2 Suppl 1):35S-42S.

19. Dragoo JL, Braun HJ, Durham JL, Ridley BA, Odegaard JI, Luong R, Arnoczky SP. Comparison of the acute inflammatory response of two commercial platelet-rich plasma systems in healthy rabbit tendons. Am J Sports Med. 2012;40(6):1274-81.

20. McCarrel TM, Minas T, Fortier LA. Optimization of leukocyte concentration in platelet-rich plasma for the treatment of tendinopathy. $\mathrm{J}$ Bone Joint Surg Am. 2012;94(19):e143(1-8)

21. Boswell SG, Schnabel LV, Mohammed HO, Sundman EA, Minas T, Fortier LA. Increasing platelet concentrations in leukocyte-reduced platelet-rich plasma decrease collagen gene synthesis in tendons. Am $\mathrm{J}$ Sports Med. 2014;42(1):42-9.

22. Giusti I, D'Ascenzo S, Mancò A, Di Stefano G, Di Francesco M, Rughetti A, Dal Mas A, Properzi G, Calvisi $\mathrm{V}$, Dolo V. Platelet concentration in platelet-rich plasma affects tenocyte behavior in vitro. BioMed Res Int. 2014;2014:630870. 
23. Jo $\mathrm{CH}$, Kim JE, Yoon KS, Shin S. Platelet-rich plasma stimulates cell proliferation and enhances matrix gene expression and synthesis in tenocytes from human rotator cuff tendons with degenerative tears. Am J Sports Med. 2012;40(5):1035-45.

24. Zhang J, Wang JH. PRP treatment effects on degenerative tendinopathy - an in vitro model study. Muscles Ligaments Tendons J. 2014;4(1):10-7.

25. Chen L, Dong SW, Tao X, Liu JP, Tang KL, XU JZ. Autologous platelet-rich clot releasate stimulates proliferation and inhibits differentiation of adult rat tendon stem cells towards nontenocyte lineages. J Int Med Res. 2012;40(4):1399-409.

26. Muto T, Kokubu T, Mifune $Y$, Sakata R, Nagura I, Nishimoto H, Harada Y, Nishida K, Kuroda R, Kurosaka M. Platelet-rich plasma protects rotator cuff-derived cells from the deleterious effects of triamcinolone acetonide. $J$ Orthop Res. 2013;31(6):976-82.

27. Carofino B, Chowaniec DM, McCarthy MB, Bradley JP, Delaronde S, Beitzel K, Cote MP, Arciero RA, Mazzocca AD. Corticosteroids and local anesthetics decrease positive effects of platelet-rich plasma: an in vitro study on human tendon cells. Arthroscopy. 2012;28(5):711-9.

28. Bausset O, Magalon J, Giraudo L, Louis ML, Serratrice N, Frere C, Magalon G, Dignat-George F, Sabatier F. Impact of local anaesthetics and needle calibres used for painless PRP injections on platelet functionality. Muscles Ligaments Tendons J. 2014;4(1):18-23.

29. Wang X, Qiu Y, Triffitt J, Carr A, Xia Z, Sabokbar A. Proliferation and differentiation of human tenocytes in response to platelet rich plasma: an in vitro and in vivo study. J Orthop Res. 2012;30(6):982-90.

30. Chung SW, Song BW, Kim YH, Park KU, Oh JH. Effect of platelet-rich plasma and porcine dermal collagen graft augmentation for rotator cuff healing in a rabbit model. Am J Sports Med. 2013;41(12):2909-18.

31. Kaux JF, Drion PV, Colige A, Pascon F, Libertiaux V, Hoffmann A, Janssen L, Heyers A, Nusgens BV, Le Goff C, Gothot A, Cescotto S, Defraigne JO, Rickert M, Crielaard JM. Effects of platelet-rich plasma (PRP) on the healing of Achilles tendons of rats. Wound Repair Regen. 2012;20:748-756

32. Fernández-Sarmiento JA, Domínguez JM, Granados MM, Morgaz J, Navarrete R, Carrillo JM, Gómez-Villamandos RJ, Muñoz-Rascón P, Martín de Las Mulas J, Millán $Y$, García-Balletbó M, Cugat R. Histological study of the influence of plasma rich in growth factors (PRGF) on the healing of divided Achilles tendons in sheep. J Bone Joint Surg Am. 2013;95(3):246-55.

33. Beck J, Evans D, Tonino PM, Yong S, Callaci JJ. The biomechanical and histologic effects of platelet-rich plasma on rat rotator cuff repairs. Am $\mathrm{J}$ Sports Med. 2012;40(9):2037-44.

34. Zhang J, Middleton KK, Fu FH, Im HJ, Wang JH. HGF mediates the anti-inflammatory effects of PRP on injured tendons. PLoS One. 2013;8(6):e67303.

35. Solchaga LA, Bendele A, Shah V, Snel LB, Kestler HK, Dines JS, Hee CK. Comparison of the effect of intratendon applications of recombinant human platelet-derived growth factor-BB, platelet-rich plasma, steroids in a rat achilles tendon collagenase model. $J$ Orthop Res. 2014;32(1):145-50.

36. Kaux JF, Janssen $L$, Drion $P$, Nusgens $B$, Libertiaux $V$, Pascon F, Heyeres A, Hoffmann A, Lambert C, Le Goff C, Denoël V, Defraigne JO, Rickert M, Crielaard JM, Colige A. Vascular Endothelial Growth Factor-111 (VEGF-111) and tendon healing: preliminary results in a rat model of tendon injury. Muscles Ligaments Tendons J. 2014;4(1):24-8.

37. Dallaudière $B$, Lempicki $M$, Pesquer $L$, Louedec $L$, Preux PM, Meyer P, Hummel V, Larbi A, Deschamps L, Journe C, Hess A, Silvestre A, Sargos P, Loriaut P, Boyer P, Schouman-Claeys E, Michel JB, Serfaty JM. Efficacy of intra-tendinous injection of platelet-rich plasma in treating tendinosis: comprehensive assessment of a rat model. Eur Radiol. 2013;23(10):2830-7.
38. Moshiri A, Oryan A. Role of platelet-rich plasma in soft and hard connective tissue healing: an evidence-based review from basic to clinical application. Hard Tissue. 2013;2(1):6.

39. Silvestre A, Huot P, Moinard M, Caillez H. Traitement des tendinopathies latérales chroniques fissuraires du coude par injection de plasma enrichi en plaquettes autologue. $J$ Traumatol Sport. 2012;29:145-55.

40. Omar AS, Ibrahim ME, Ahmed AS, Said M. Local injection of autologous platelet rich plasma and corticoid in treatment of lateral epicondylitis and plantar fasciitis: randomized clinical trial. Egypt Rheum. 2012(34):43-9.

41. Chaudhury S, de La Lama M, Adler RS, Gulotta LV, Skonieczki B, Chang A, Moley P, Cordasco F, Hannafin J, Fealy S. Platelet-rich plasma for the treatment of lateral epicondylitis: sonographic assessment of tendon morphology and vascularity (pilot study). Skeletal Radiol. 2013;42(1):91-7

42. Krogh TP, Fredberg $\mathrm{U}$, Stengaard-Pedersen $\mathrm{K}$, Christensen R, Jensen P, Ellingsen T. Treatment of lateral epicondylitis with platelet-rich plasma, glucocorticoid, or saline: a randomized, double-blind, placebo-controlled trial. Am J Sports Med. 2013;41(3):625-35.

43. Mishra AK, Skrepnik NV, Edwards SG, Jones GL, Sampson S, Vermillion DA, Ramsey ML, Karli DC, Rettig AC. Efficacy of platelet-rich plasma for chronic tennis elbow: a double-blind, prospective, multicenter, randomized controlled trial of 230 patients. Am J Sports Med. 2014;42(2):463-71.

44. Rha DW, Park GY, Kim YK, Kim MT, Lee SC. Comparison of the therapeutic effects of ultrasound-guided platelet-rich plasma injection and dry needling in rotator cuff disease: a randomized controlled trial. Clin Rehabil. 2013;27(2):11322.

45. Kesikburun S, Tan AK, Yilmaz B, Yasar E, Yazicioglu K. Platelet-rich plasma injections in the treatment of chronic rotator cuff tendinopathy: a randomized controlled trial with 1-year follow-up. Am J Sports Med. 2013;41(11):2609-16.

46. de Almeida AM, Demange MK, Sobrado MF, Rodrigues MB, Pedrinelli A, Hernandez AJ. Patellar Tendon Healing With Platelet-Rich Plasma: A Prospective Randomized Controlled Trial. Am J Sports Med. 2012;40(6):1282-8.

47. Gosens $T$, Den Oudsten BL, Fievez E, van 't Spijker $P$, Fievez A. Pain and activity levels before and after plateletrich plasma injection treatment of patellar tendinopathy: a prospective cohort study and the influence of previous treatments. Int Orthop. 2012;36:1941-6.

48. Rowan TL, Drouin JL. A multidisciplinary approach including the use of platelet-rich plasma to treat an elite athlete with patellar tendinopathy - a case report. J Can Chiro Ass. 2013;57(4):301-9.

49. Filardo G, Kon E, Di Matteo B, Pelotti P, Di Martino A, Marcacci M. Platelet-rich plasma for the treatment of patellar tendinopathy: clinical and imaging findings at medium-term follow-up. Int Orthop. 2013;37(8):1583-9.

50. Vetrano M, Castorina A, Vulpiani MC, Baldini R, Pavan A, Ferretti A. Platelet-rich plasma versus focused shock waves in the treatment of jumper's knee in athletes. Am J Sports Med. 2013;41(4):795-803.

51. Dragoo JL, Wasterlain AS, Braun HJ, Nead KT. Plateletrich plasma as a treatment for patellar tendinopathy: a double-blind, randomized controlled trial. Am J Sports Med. 2014;42(3):610-8.

52. Charousset C, Zaoui A, Bellaiche L, Bouyer B. Are Multiple Platelet-Rich Plasma Injections Useful for Treatment of Chronic Patellar Tendinopathy in Athletes?: A Prospective Study. Am J Sports Med. 2014;42(4):906-11

53. Kaux JF, Croisier JL, Bruyere O, Rodriguez de la Cruz C, Forthomme B, Brabant G, Lapraille S, Lonneux V, Noel D, Le Goff C, Gothot A, Collette J, Crielaard JM. One injection of platelet-rich plasma associated to a submaximal eccentric protocol to treat chronic jumper's knee. J Sports Med Phys Fitness. 2014 Jun 19. [Epub ahead of print]

54. van Ark M, van den Akker-Scheek I, Meijer LT, Zwerver J. An exercise-based physical therapy program for patients 
with patellar tendinopathy after platelet-rich plasma injection. Phys Ther Sport. 2013;14(2):124-30.

55. Kaux JF, Forthomme B, Namurois MH, Bauvir P, Defawe N, Delvaux F, Lehance C, Crielaard JM, Croisier JL. Description of a standardized rehabilitation program based on sub-maximal eccentric following a platelet-rich plasma infiltration for jumper's knee. Muscles Ligaments Tendons J. 2014;4(1):85-9.

56. Bowman KF, Jr., Muller B, Middleton K, Fink C, Harner $\mathrm{CD}, \mathrm{Fu} \mathrm{FH}$. Progression of patellar tendinitis following treatment with platelet-rich plasma: case reports. Knee Surg Sports Traumatol Arthrosc. 2013;21(9):2035-9.

57. Kaux JF, Croisier JL, Leonard P, Le Goff C, Crielaard JM. Exuberant Inflammatory Reaction as a Side Effect of Platelet-Rich Plasma Injection in Treating One Case of Tendinopathy. Clin J Sport Med. 2014; 24(2):150-2.

58. Silvestre A, Peuchant A, Bausset O, Magalon J, Magalon $G$, Serratrice N. Achilles tendinopathy recovery after a single autologous PRP injection monitored by ultrasound. J Traumatol Sport. 2014;31:94-100.

59. Filardo G, Kon E, Di Matteo B, Di Martino A, Tesei G, Pelotti P, Cenacchi A, Marcacci M. Platelet-rich plasma injections for the treatment of refractory Achilles tendinopathy: results at 4 years. Blood Transfu. 2014:1-8.

60. Murawski CD, Smyth NA, Newman H, Kennedy JG. A single platelet-rich plasma injection for chronic midsubstance achilles tendinopathy: a retrospective preliminary analysis. Foot Ankle Spec. 2014;7(5):372-6.

61. de Vos RJ, Weir A, van Schie HT, Bierma-Zeinstra SM, Verhaar JA, Weinans $\mathrm{H}$, Tol JL. Platelet-rich plasma injection for chronic Achilles tendinopathy: a randomized controlled trial. JAMA. 2010;303(2):144-9.

62. Whitman $\mathrm{DH}$, Berry RL, Green DM. Platelet gel: an autologous alternative to fibrin glue with applications in oral and maxillofacial surgery. J Oral Maxillofac Surg.1997;55(11):1294-9.

63. Sanchez M, Anitua E, Orive G, Mujika I, Andia I. Plateletrich therapies in the treatment of orthopaedic sport injuries. Sports Med. 2009;39(5):345-54.

64. Dohan Ehrenfest DM, Rasmusson L, Albrektsson T. Classification of platelet concentrates: from pure plateletrich plasma (P-PRP) to leucocyte- and platelet-rich fibrin (L-PRF). Trends Biotechnol. 2009;27(3):158-67.

65. Kaux JF, Le Goff C, Renouf J, Peters P, Lutteri L, Gothot A, Crielaard JM. Comparison of the platelet concentrations obtained in platelet-rich plasma (PRP) between the GPS II and GPS III systems. Pathol Biol (Paris). 2011;59(5):275-7.

66. Kaux JF, Le Goff C, Seidel L, Péters P, Gothot A, Albert A, Crielaard JM. [Comparative study of five techniques of preparation of platelet-rich plasma]. Pathol Biol (Paris). 2011;59(3):157-60.

67. Dohan Ehrenfest DM, Andia I, Zumstein MA, Zhang CQ, Pinto NR, Bielecki T. Classification of platelet concentrates (Platelet-Rich Plasma-PRP, Platelet-Rich Fibrin-PRF) for topical and infiltrative use in orthopedic and sports medicine: current consensus, clinical implications and perspectives. Muscles Ligaments Tendons J. 2014;4(1):39.

68. Kaux JF, Drion P, Libertiaux V, Colige A, Hoffmann A Nusgens B, Besançon B, Forthomme B, Le Goff C Franzen R, Defraigne JO, Cescotto S, Rickert M, Crielaard $\mathrm{JM}$, Croisier JL. Eccentric training improves tendon biomechanical properties: A rat model. J Orthop Res. 2013;31(1):119-24.
69. Weibrich G, Kleis WK, Hitzler WE, Hafner G. Comparison of the platelet concentrate collection system with the plasma-rich-in-growth-factors kit to produce platelet-rich plasma: a technical report. Int $\mathrm{J}$ Oral Maxillofac Implants. 2005;20(1):118-23.

70. Anitua E, Sanchez M, Prado R, Orive G. The type of platelet-rich plasma may influence the safety of the approach. Knee Surg Sports Traumatol Arthrosc. 2014;22(7):1708-9.

71. Pizza FX, McLoughlin TJ, McGregor SJ, Calomeni EP, Gunning WT. Neutrophils injure cultured skeletal myotubes. Am J Physiol Cell Physiol. 2001;281(1):C335-41.

72. Jiang N, Tan NS, Ho B, Ding JL. Respiratory proteingenerated reactive oxygen species as an antimicrobial strategy. Nat Immunol. 2007;8(10):1114-22.

73. de Vos RJ, Tol JL, Verhaar J. Platelet-rich plasma for treatment of Achilles tendinopathy. JAMA. 2010;303(17):1697-8.

74. Brown J, Sivan M. Ultrasound-guided platelet-rich plasma injection for chronic patellar tendinopathy: a case report. PM R. 2010;2(10):969-72.

75. Engebretsen L, Steffen K, Alsousou J, Anitua E, Bachl N, Devilee R, Everts P, Hamilton B, Huard J, Jenoure $P$, Kelberine F, Kon E, Maffulli N, Matheson G, MeiDan O, Menetrey J, Philippon M, Randelli $P$, Schamasch P, Schwellnus M, Vernec A, Verrall G. IOC consensus paper on the use of platelet-rich plasma in sports medicine. $\mathrm{Br} \mathrm{J}$ Sports Med. 2010;44(15):1072-81.

76. Wiegerinck JI, Reilingh ML, de Jonge MC, van Dijk $\mathrm{CN}$, Kerkhoffs GM. Injection techniques of platelet-rich plasma into and around the Achilles tendon: a cadaveric study. Am J Sports Med. 2011;39(8):16816.

77. Finnoff JT, Fowler SP, Lai JK, Santrach PJ, Willis EA, Sayeed YA, Smith J. Treatment of chronic tendinopathy with ultrasound-guided needle tenotomy and platelet-rich plasma injection. PM R. 2011;3(10):900-11.

78. Roukis TS, Zgonis T, Tiernan B. Autologous plateletrich plasma for wound and osseous healing: a review of the literature and commercially available products. Adv Ther. 2006;23(2):218-37.

79. Ljungqvist $A$, Schwellnus MP, Bachl N, Collins $M$, Cook J, Khan KM, Maffulli N, Pitsiladis Y, Riley G, Golspink G, Venter D, Derman EW, Engebretsen L, Volpi P. International Olympic Committee consensus statement: molecular basis of connective tissue and muscle injuries in sport. Clin Sports Med. 2008;27(1):231-9.

80. Engebretsen E, Schamasch P. The Use of PlateletRich Plasma in Sports Medicine-the International Olympic Committee Opinion. Operative Techniques Orthopaedics. 2012;22(1):43-8.

81. Loftus ML, Endo Y, Adler RS. Retrospective analysis of postinjection ultrasound imaging after platelet-rich plasma or autologous blood: observational review of anatomic distribution of injected material. AJR Am J Roentgenol. 2012;199(4):W501-5.

82. Sheth U, Simunovic N, Klein G, Fu F, Einhorn TA, Schemitsch E, Ayeni OR, Bhandari M.. Efficacy of autologous platelet-rich plasma use for orthopaedic indications: a meta-analysis. J Bone Joint Surg Am. 2012;94(4):298-307. 


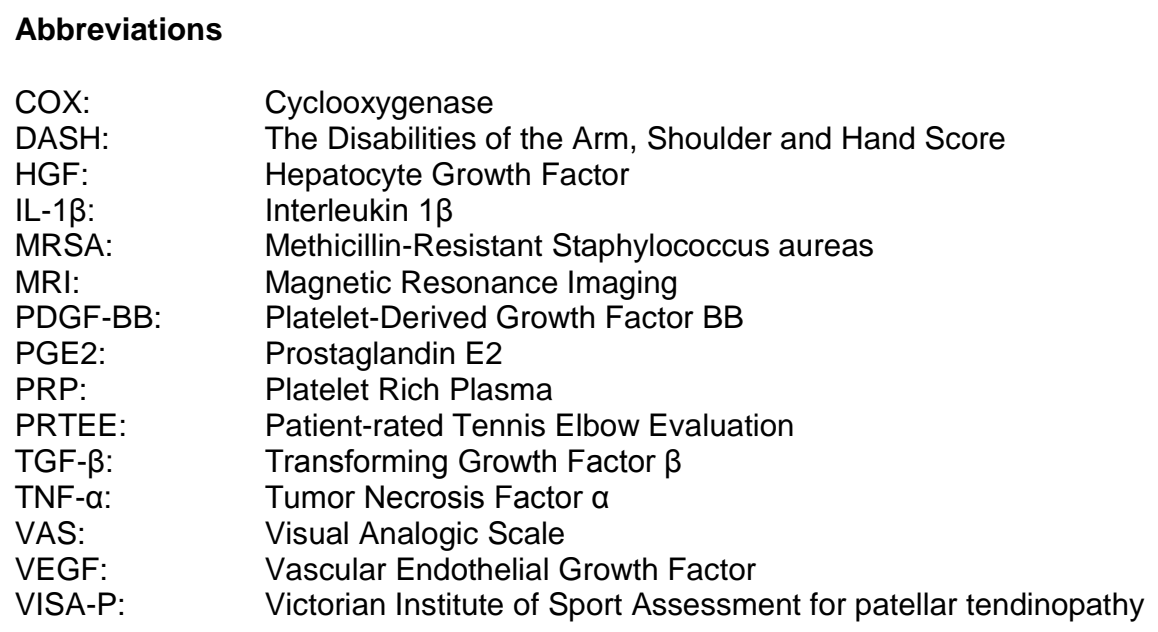

\section{Potential Conflicts of Interests}

None

\section{Corresponding Author}

KAUX Jean-François, Physical Medicine and Sport Traumatology, University Hospital of Liège, Avenue de l'Hôpital, B35, 4000 Liège, Belgium, e-mail: jfkaux@chu.ulg.ac.be 